\title{
A Note on Democracy and Competition: The Role of Ownership Structure in a General Equilibrium Model with Vertical Preferences *
}

\author{
Hend Ghazzai ${ }^{\dagger} \quad$ Wided Hemissi ${ }^{\ddagger} \quad$ Rim Lahmandi-Ayed ${ }^{\S}$ \\ Sana Mami Kefi
}

This note considers a general equilibrium model where individuals are potentially consumers, workers, and shareholders. It extends the results obtained previously by Kahloul et al. (2017) with extreme ownership structures on the majority vote between Monopoly and Duopoly, to the case of any proportion of shareholders in the population.

We prove that Duopoly is preferred when non-shareholders constitute a majority of the population. Otherwise, the majority vote depends on the proportion of shareholders and the dispersion of the individuals with respect to their intensity of preference for quality relative to their sensitivity to effort.

Keywords: Imperfect Competition, Democracy, Vertical Differentiation, General Equilibrium, Ownership Structure.

\footnotetext{
*We are grateful to an anonymous referee for his/her helpful comments.

†Corresponding Author. Mediterranean School of Business - South Mediterranean University and U.R. MASE-ESSAI. Les Jardins du Lac 2, 1053 Tunis, Tunisia. Email: hend.ghazzai@msb.tn. Tel:+216 711944 44, Ext:237

${ }_{\ddagger}^{\ddagger}$ Mediterranean School of Business - South Mediterranean University. Email: wided.hemissi@msb.tn

§University of Carthage, ESSAI, UR14ES13, U.R. MASE, 6, rue des métiers, La Charguia 2, 1080 Tunis, Tunisia. Email: rim.lahmandi@polytechnique.org, rim.lahmandi.ayed@gmail.com

IMediterranean School of Business - South Mediterranean University. Email: sana.mami@msb.tn
} 


\section{Concurrence et démocratie: une note sur le rôle de la structure de propriété dans un modèle d'équilibre général avec des préférences verticales}

Dans cette note, on étudie un modèle d'équilibre général où les individus sont potentiellement des consommateurs, des travailleurs et des actionnaires. On généralise le travail de Kahloul et al. (2017) qui détermine le résultat d'un vote majoritaire entre Monopole et Duopole pour deux structures de propriété particulières extrêmes, en considérant une proportion quelconque d'actionnaires dans la population.

On montre que le Duopole est préféré lorsque les non-actionnaires représentent une majorité dans la population. Autrement, le résulat du vote majoritaire dépend de la proportion d'actionnaires et de la dispersion des individus par rapport à leur intensité de préférence pour la qualité relativement à leur despersion par rapport à leur sensibilité à l'effort.

Mots-clés: Compétition Imparfaite, Démocratie, Différenciation Verticale, Equilibre Général, Structure de propriété.

JEL Classification: D7, L13.

\section{Introduction}

The main question in this note is to examine under which conditions, in particular with respect to the ownership structure, direct democratic choice favors competition. In other words, we study how the ownership structure affects democratic choice between more and less competition.

We consider an economy with firms producing a vertically differentiated product using labor as the unique input and a population of heterogeneous citizens who are potentially workers, consumers and shareholders. Citizens differ with respect to their preference for quality, their sensitivity to effort, and their ownership status (shareholders or non-shareholders). In a general equilibrium setting, they are asked to choose between Monopoly and Duopoly through direct vote.

This paper is an extension of the work of Kahloul et al. (2017) who address the same question and use the same model with two extreme ownership structures: (1) concentrated ownership: where the number of shareholders in negligible and (2) egalitarian ownership: where all citizens share equally the firms. We allow in this work the proportion of shareholders to take any value between 0 and 1 . Thus, we have two groups of citizens: shareholders and non-shareholders. The ownership structures examined in Kahloul et al. (2017) appear now as two particular cases of our model.

When choosing between Monopoly and Duopoly, citizens have to weigh the positive effect of competition on wages and prices and its negative effect on profits. The 
results of the vote depend on the proportion of shareholders in the economy and the relative dispersion of citizens with respect to their preferences for quality and their sensitivity to effort. The majority vote is for more competition if non-shareholders are a majority. If shareholders are the majority, the majority vote depends on the proportion of shareholders and the dispersion of the individuals with respect to their intensity of preference for quality relative to their sensitivity to effort.

Kahloul et al. (2017) provide an extensive literature review. Two main research streams are related to our paper: (1) vertical differentiation models in a partial equilibrium framework and (2) general equilibrium models with product differentiation. When labor is integrated in the models of the first stream as in Bacchiega (2007), Gabszewicz and Turrini (1999, 2000), and Hili et al. (2015), workers and consumers are considered as separate categories of agents. In our paper, individuals are potentially workers and/or consumers. The general equilibrium models of the second stream do not specifically consider vertical differentiation (Cornet and Medecin, 2006). When vertical differentiation is included as in Lutz and Turrini (2006), there is no decentralized social choice to be made. While the last paper examines the effects of skills endowment, wages, and labour taxation on the industry profits, we analyze the decentralized choice between Monopoly and Duopoly through majority vote.

The remainder of the paper is organized as follows. Section 2 describes the model and gives some preliminary results about the equilibria in the Monopoly and Duopoly cases. In section 3, we provide the results on the majority vote outcome. We conclude in section 4. An outline of the proof is given in Appendix.

\section{Model And Preliminary Results}

Our model is an extension of Kahloul et al. (2017). We consider an economy where labor is the unique input and where the only output is an indivisible differentiated good. Producing one unit of the differentiated good requires one unit of labor (thus, costs have constant returns to scale). The population is made of individuals who are potentially consumers, workers and shareholders. Each individual is endowed with one unit of labor and a quantity of numeraire $e$. Heterogeneity among individuals is three-fold. Each individual is characterized by: (1) his/her sensitivity to effort $\alpha \in[0, \bar{\alpha}] ;(2)$ his/her intensity of preference for the product quality $\theta \in[0, \bar{\theta}]$ and (3) his/her ownership status i.e. whether he/she owns shares in the firms or not.

We assume that individuals are uniformly distributed over $[0, \bar{\alpha}] \times[0, \bar{\theta}]$ with a density normalized to 1 .

We denote by $\mu$ the proportion of the population who owns the firm(s). Note that we assume that shareholders are uniformly distributed over the whole population and that they share equally the firms. This is the way we extend Kahloul et al. (2017). While they focus on extreme ownership scenarios where $\mu=1$ (all individuals are shareholders) or $\mu=0$ (shareholders are negligible), we allow $\mu$ to take any value between 0 and 1 . 
We denote by $\lambda \geqslant 0$ the individual share in the firms' profit. Each shareholder holds the proportion $\lambda=\frac{1}{\mu \bar{\alpha} \bar{\theta}}$ in the firms' profit. For non-shareholders, $\lambda=0$. The lower the proportion of shareholders $\mu$, the higher their share in the firms' profit.

We model two market structures: a Monopoly and a Duopoly.

Under each market structure, each individual makes first the choice between remaining idle $(\bar{W})$ and working (and if so, he chooses between Firms 1 and 2 under Duopoly.) He second chooses between not consuming $(\bar{C})$ and consuming one unit of the differentiated product (and if so, he chooses between the products of Frms 1 and 2 under Duopoly.) Compared to Monopoly, Duopoly offers more options both in terms of work and consumption.

The individual utility is derived from the consumption of the differentiated product and a composite numeraire and is expressed as follows:

$$
V(x, t)=\theta q x+t
$$

where $x$ is the consumption of the differentiated product of quality $q$ and $t$ is the consumption of the numeraire good. The consumption bundle $(x, t)$ belongs to the consumption set $\{0,1\} \times \mathbb{R}$. Individuals with a high intensity of preference for the quality $(\theta)$ are more impacted by the quality level $(q)$.

Individuals receive income from three potential sources: the initial endowment $e$ supposed to be the same for all individuals, the wage $w$ if they decide to participate in the labor market, and the dividends if they are shareholders. We further assume that individuals will have to incur an effort or training cost $\alpha q$ if they decide to work in a firm producing quality $q$. Higher qualities are thus assumed to require higher effort/training and for a given quality, higher sensitivity to effort $\alpha$ translates into higher training cost. An individual who chooses not to work receives no wage and is not subject to training cost.

Under Monopoly, the firm chooses its price $p$ and quality $q$ of its product so as to maximize its profit. Under Duopoly, two firms compete choosing, in a standard two-step game, qualities $q_{i}$ then prices $p_{i}(i \in\{1,2\})$. Qualities are chosen from a given interval $[0, \bar{q}]$. Wages are endogenously determined by balancing the supply and demand on the labor market.

The equilibrium outcomes under Monopoly and Duopoly are the same as in Kahloul et al. (2017) as they do not depend on the ownership structure. They are reminded in Kahloul et al. Results 1 and 2 ,

Kahloul et al.: Result 1 (Monopoly Equilibrium) At equilibrium, the Monopoly chooses to produce $q_{m}^{*}=\bar{q}$, charges price $p_{m}^{*}=\frac{\bar{\theta} \bar{q}(\bar{\theta}+2 \bar{\alpha})}{2(\bar{\theta}+\bar{\alpha})}$ and makes the profit $\pi_{m}^{*}=\frac{\bar{\alpha} \bar{\theta}^{3} \bar{q}}{4(\bar{\theta}+\bar{\alpha})}$. Workers receive a wage $w_{m}^{*}=\frac{\bar{\alpha} \bar{\theta}}{2(\bar{\theta}+\bar{\alpha})}$.

Kahloul et al.: Result 2 (Duopoly Equilibrium) Under Duopoly, the equilibrium qualities, prices, wages and profits are given by: 
- Firm 1: $q_{1}^{*}=\frac{4}{7} \bar{q} ; p_{1}^{*}=\frac{\bar{\theta} \bar{q}(\bar{\theta}+8 \bar{\alpha})}{14(\bar{\theta}+\bar{\alpha})} ; w_{1}^{*}=\frac{\bar{\alpha} \bar{q} \bar{q}}{2(\bar{\theta}+\bar{\alpha})}$ and $\pi_{1}^{*}=\frac{\bar{\alpha} \bar{\theta}^{3} \bar{q}}{48(\bar{\theta}+\bar{\alpha})}$,

- Firm 2: $q_{2}^{*}=\bar{q} ; p_{2}^{*}=\frac{\bar{\theta} \bar{q}(\bar{\theta}+4 \bar{\alpha})}{4(\bar{\theta}+\bar{\alpha})} ; w_{2}^{*}=\frac{3 \bar{\alpha} \bar{q}}{4(\bar{\theta}+\bar{\alpha})}$ and $\pi_{2}^{*}=\frac{7 \bar{\alpha} \bar{\theta}^{3} \bar{q}}{48(\bar{\theta}+\bar{\alpha})}$.

The comparison between the Monopoly and Duopoly outcomes is given in Corollary 1. The proof of Corollary 1 is omitted as it is obtained through simple calculations.

Corollary 1 (Comparison of the Equilibria Outcomes ) Comparing the results of equilibria obtained under Monopoly and Duopoly, we have:

- Price of the highest quality: $p_{2}^{*}<p_{m}^{*}$;

- Wages: $w_{1}^{*}=w_{m}^{*}$ and $w_{2}^{*}>w_{m}^{*}$;

- Profits: $\pi_{1}^{*}+\pi_{2}^{*}<\pi_{m}^{*}$;

- Marginal consumers: $0<\frac{p_{1}^{*}}{q_{1}^{*}}<\frac{p_{2}^{*}-p_{1}^{*}}{q_{2}^{*}-q_{1}^{*}}<\frac{p_{m}^{*}}{q_{m}^{*}}<\bar{\theta}$;

- Marginal Workers: $0<\frac{w_{m}^{*}}{q_{m}^{*}}<\frac{w_{2}^{*}-w_{1}^{*}}{q_{2}^{*}-q_{1}^{*}}<\frac{w_{1}^{*}}{q_{1}^{*}}<\bar{\alpha}$.

Competition affects the interest of citizens in several ways. Namely, citizens are positively impacted by competition as consumers and workers but are negatively affected as shareholders.

As consumers, citizens have access under Duopoly to the highest quality $\bar{q}$ at a lower price compared to Monopoly. They have additionally the option to buy a lower quality. As workers, more competition provides an additional option of work and raises wages, therefore encouraging more citizens to participate in the labor market. As shareholders, citizens are negatively affected by more competition as the fiercer the competition, the lower the profits. According to the effects described above, the overall effect of competition on non-shareholders is positive and is ambiguous for shareholders. Hence, shareholders face a trade-off between the positive and negative effects of more competition when deciding to vote for Monopoly Duopoly while nonshareholders clearly vote for Duopoly.

\section{The vote outcome}

In this section we present the outcome of the vote. To do so, we first determine the indirect utility of each individual at equilibrium under each market structure (Monopoly and Duopoly), depending of his/her status in terms of consumption and work, thus on his/her position relative to the marginal consumers and workers. We then examine the individual decision of any citizen $(\alpha, \theta)$ by comparing his/her indirect utility under Monopoly with his/her utility under Duopoly. Finally, we count the number of votes for Duopoly and check whether it exceeds half the population. 
Denote by $\delta=\frac{\bar{\theta}}{\bar{\alpha}}$ the relative dispersion of the citizens with respect to their intensity of preference for quality and their sensitivity to effort.

Our core result in Proposition 1 below summarizes the outcome of this comparison.

Proposition 1 (Votes' Results) Depending on the ownership parameter $\mu$ and the relative dispersion $\delta$, the majority vote is described below:

- if $\mu<\frac{1}{2}$ (majority of non-shareholders): citizens vote in majority for Duopoly.

- if $\frac{1}{2}<\mu<1$ (majority of shareholders), there exists a unique $\delta_{\mu}<2 \mu$ such that the majority votes for Monopoly when $\delta<\delta_{\mu}$, and for Duopoly otherwise. $\delta_{\mu}$ is the unique solution of $D(\delta, \mu)=0$; where $D(\delta, \mu)=2304 \mu(2 \mu-1)+$ $96 \mu(12 \mu-41) \delta+36 \mu(2 \mu-43) \delta^{2}+7(7+12 \mu) \delta^{3}$.

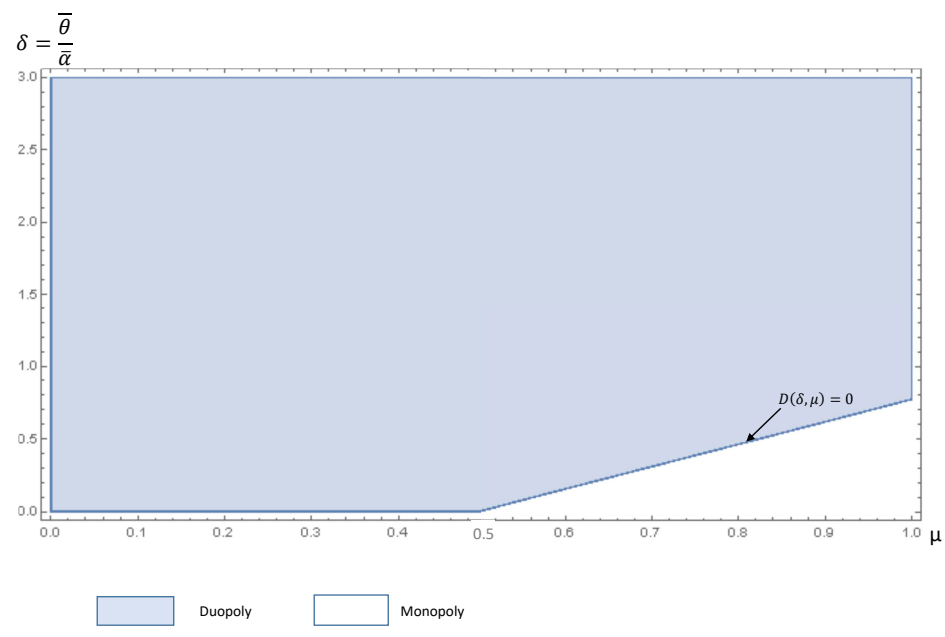

Figure 1: Majority vote outcome in the space $(\mu, \delta)$.

Non-shareholders always prefer Duopoly to Monopoly as they are only affected by consumption and work effects which are in favor of Duopoly. Shareholders have to weigh the positive work/consumption effects of the Duopoly setting and the negative effect of competition on their profits' shares.

When non-shareholders are majority, the majority vote is for Duopoly. When shareholders are majority, we have to determine their votes and count among them the number of votes for Duopoly to be added to the number of non-shareholders. 
Figure 1 depicts the results of Proposition 1 The majority choice is for Monopoly only if shareholders are majority and individuals are much more dispersed with respect to their sensitivity to effort than with respect to their preference for quality $($ small $\delta)$. In all other cases, the majority vote is in favor of Duopoly. Recall that $\delta$ is defined to be the fraction $\frac{\bar{\theta}}{\bar{\alpha}}$.

The ownership parameter $\mu$ affects the results of the votes, playing a double role: (1) it represents the proportion of shareholders over the population and (2) it determines the share in firms' profits of each shareholder. It has thus two opposite effects on the vote outcome: (1) the higher $\mu$, the higher the proportion of shareholders i.e. the higher the number of citizens who may potentially favor Monopoly because of the negative effect of competition on the profits but (2) the lower their share in firms' profit i.e. the less important is the negative shareholders' effect in the indirect utility function of shareholders.

The cutoff value $\delta_{\mu}$ represents the relative dispersion of individuals with respect to their intensity of preference for quality and their sensitivity to effort that perfectly balances the proportion of shareholders who prefer Monopoly and the rest of the population who prefers Duopoly. For any $\delta$ below $\delta_{\mu}$, the shareholders who prefer Monopoly are majority. It is worth noting as shown in Figure 1 that $\delta_{\mu}$ is increasing with respect to $\mu$. Therefore, the higher $\mu$, the wider the range of $\delta\left(\delta \in\left[0, \delta_{\mu}\right]\right)$ that leads to a majority vote for Monopoly. Indeed, the higher the proportion of shareholders (the only who may support Monopoly), the more likely the vote for Monopoly.

To understand the political forces at stake, consider for instance the case of a sufficiently small $\delta$, precisely for ${ }^{1} \delta<2 \mu$. Figure 2 gives in this case the result of the vote of each shareholder in the space $(\alpha, \theta)$. Areas of Figure 2 are defined in Appendix. Shareholders of Area 4 who are extremely sensitive to effort and have low preferences for quality always vote for Monopoly. Indeed, they neither work nor consume under both settings and solely base their vote decisions on their profit shares which are higher under Monopoly. The relative size of this category of shareholders among all shareholders is given by: $\frac{1}{\bar{\theta} \bar{\alpha}}\left(\bar{\alpha}-\frac{\omega_{1}^{*}}{q_{1}^{*}}\right) \frac{p_{1}^{*}}{q_{1}^{*}}=\frac{(\delta+8)^{2}}{64(\delta+1)^{2}}$ which is decreasing with $\delta$ and converging to 1 when $\delta$ goes to 0 . Moreover, a small $\delta$ means a small $\bar{\theta}$ and/or a high $\bar{\alpha}$. The smaller $\bar{\theta}$, the more there are individuals choosing not to consume. The higher $\bar{\alpha}$, the more there are individuals choosing not to work. This explains why Area 4 is of a big size when $\delta$ is small.

The lower $\delta$, the bigger the size of Area 4 which drives the majority vote in favor of Monopoly. The higher $\delta$, the smaller the size of this area and the higher the size of other categories of shareholders who may prefer Duopoly either from work, consumption perspective, or both. Among them, the relative size of Areas 9 to 16 is given by $\frac{1}{\bar{\theta} \bar{\alpha}}\left(\bar{\theta}-\frac{p_{2}^{*}-p_{1}^{*}}{q_{2}^{*}-q_{1}^{*}}\right) \bar{\alpha}=\frac{7 \delta}{12(\delta+1)}$ which is increasing with $\delta$, converging to 0 when $\delta$ goes to 0 and to $\frac{7}{12}$ as $\delta$ goes to infinity. This means that as $\delta$ becomes high enough, the weight of this group among shareholders becomes majoritarian, driving

\footnotetext{
${ }^{1}$ You may find more details in Appendix.
} 
the majority vote for Duopoly.

The preceding reasoning applies for any fixed $\mu>\frac{1}{2}$. The number of votes for Duopoly is equal to the number of non-shareholders to which we add the number of shareholders who prefer Duopoly. But the latter is decreasing with their proportion $\mu$ as explained earlier; hence the increase of $\delta_{\mu}$ with respect to $\mu$.

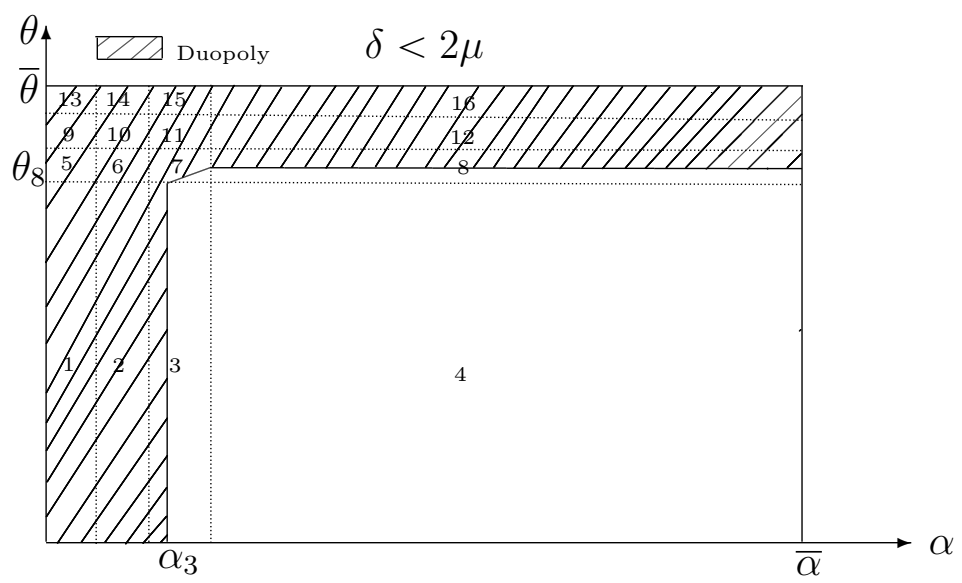

Figure 2: Shareholders' votes for small enough $\delta$.

\section{Conclusion}

This note examines whether a democratic choice leads to more or less competition. More precisely, we consider a general equilibrium model where individuals are differentiated with respect to their intensity of preference for quality, their sensitivity to effort, and their ownership status. We study within this framework, the individual choices between Monopoly and Duopoly and we deduce the outcome of the majority vote.

We prove that the majority choice is for Monopoly only if shareholders are majority and individuals are much more dispersed with respect to their sensitivity to effort than with respect to their preference for quality. In all the other cases, the majority vote is in favor of Duopoly.

In this note, following Kahloul et al. (2017), we assume a Bertrand competition between firms under the Duopoly market structure. One extension of this note would be to reexamine the results while assuming a competition à la Cournot. We may also allow consumers to buy more than one unit of the differentiated good. Another issue of importance is the profit maximization hypothesis which becomes questionable when an important fraction of shareholders are also workers and consumers. This has already been addressed in the case of monopoly in Lahmandi-Ayed and Laussel (2018). The profit maximization assumption is even more questionable in 
the duopoly case as shareholders have equal shares in both firms. ${ }^{2}$ The question may be of interest in a future work. Finally, the model adopted in this note may be easily adapted to deal with development economics issues such as poverty. It has been done by Kahloul, Lahmandi-Ayed and Lasram (2019) who established results on the effect of more competition on poverty, considering two extreme ownership structures. One may try to extend their results to the more general property structure adopted here.

\section{References}

Anderson, S.P., de Palma, A., Thisse, J.F. [1992], Discrete Choice Theory of Product Differentiation, Cambridge(MA), MIT Press.

Bacchiega, E. [2007], Wage Bargaining and Vertical Differentiation, International Review of Economics, 54, 35-52.

Choi, C.J., Shin, H.S. [1992], A Comment on a Model of Vertical Product Differentiation, Journal of Industrial Economics, 40, 229-231.

Cornet, B., Medecin, J.P. [2006], A General Equilibrium Model of Spatial Economics: The Case of Finite Locations, Cahiers de la MSE, Série Bleue du CERMSEM, 2002.101 .

Gabszewicz, J., Turrini, A. [1999], Workers' Skills and Product Selection, Revue Economique, 50, 383-391.

Gabszewicz, J., Turrini, A. [2000], Workers' Skills, Product Quality and Industry Equilibrium, International Journal of Industrial Organization, 18, 575-593.

Hili, A., Lahmandi-Ayed, R., Lasram, H. [2015], Vertical Differentiation and Labor Market : The Differentiation Principle Revisited, Economics Bulletin, 35, 633-640.

Kahloul, A., Lahmandi-Ayed, R., Lasram, H. [2019], Poverty, Competition, Democracy and Ownership: a General Equilibrium Model with Vertical Preferences. Journal of Public Economic Theory, 21, 1143-1178.

Kahloul, A., Lahmandi-Ayed, R., Lasram, H., Laussel D. [2017], Democracy and Competition: Vertical Differentiation and Labor in a General Equilibrium Model, Journal of Public Economic Theory, 19(4), 860-874.

Lahmandi-Ayed, R. [2001], Oligopoly Equilibria in Exchange Economies: A Limit Theorem, Economic Theory, 17, 665-674.

\footnotetext{
${ }^{2}$ We are grateful to an anonymous referee for this remark.
} 
Lahmandi-Ayed, R., Laussel, D. [2018], When Do Imperfectly Competitive Firms Maximize Profits? The Lessons from a Simple General Equilibrium Model with Shareholders' Voting, Journal of Mathematical Economics, 78, 6-12.

Lutz, S., Turrini, A. [2006], A General Equilibrium Model with Vertically Differentiated Industries, Skilled Labour and Trade, Economic Modelling, 23, 1-19.

Mussa, M., Rosen, S. [1978], Monopoly and Product Quality, Journal of Economic Theory, 18, 301-317.

Wauthy, X. [1996], Quality Choice in Models of Vertical Differentiation, Journal of Industrial Economics, 44, 345-353.

\section{Appendix: Proof of Proposition 1}

We provide in this section an outline of the proof of Proposition 1. We proceed in two steps ${ }^{3}$

- Step 1: Depending on the level of prices and salaries, and on his/her type, an individual makes his/her choices in terms of work and consumption. At the Monopoly equilibrium, he/she may work $(W)$ or not $(\bar{W})$ and may consume $(C)$ or not $(\bar{C})$. This divides $[0, \bar{\alpha}] \times[0, \bar{\theta}]$ into 4 zones. At the Duopoly equilibrium, the individual chooses between remaining idle $(\bar{W})$, working in Firm $1\left(W_{1}\right)$ and working in Firm $2\left(W_{2}\right)$ and chooses between not consuming $(\bar{C})$, consuming from Firm $1\left(C_{1}\right)$ and consuming from Firm $2\left(C_{2}\right)$. This divides $[0, \bar{\alpha}] \times[0, \bar{\theta}]$ into 9 zones. Superimposing both divisions leads to a division into 16 zones identified in Figure 3. In each zone, the utility under Monopoly and under Duopoly are identified and compared ${ }^{4}$.

- Step 2: We count the number of shareholders who prefer Monopoly. We then compare that number to half of the population size $\frac{1}{2} \bar{\theta} \bar{\alpha}$ to conclude whether the majority votes for Monopoly or Duopoly. We study the sign of $U_{D}-U_{M}$ and determine the majority vote only for $\mu \in] \frac{1}{2}$, 1] i.e. there is a majority of shareholders. When $\mu \in\left[0, \frac{1}{2}\right]$, there is a majority of non-shareholders and the majority vote is therefore for Duopoly as it is preferred by all non-shareholders.

\section{Outline of Proof of Proposition 1: Step 1}

We provide the sign of $U_{D}-U_{M}$ given by Figure 3 in Area 6 . The sign of the utility difference in all other areas is found using the same procedure. In area 6 , the utility difference is $U_{D}\left(W_{2}, C_{1}\right)-U_{M}(\bar{W}, \bar{C})=\frac{\bar{\theta} \bar{q}}{84(\bar{\theta}+\bar{\alpha})}\left[15 \bar{\alpha}-\left(6+\frac{1}{7 \mu}\right) \bar{\theta}\right]+\left(\frac{4}{7} \theta-\alpha\right) \bar{q}$. We

\footnotetext{
${ }^{3}$ The complete proof is available upon request.

${ }^{4}$ For more details about individuals' working and consumption decisions, see Lemmas A1 and A3 in Kahloul et al(2017).
} 


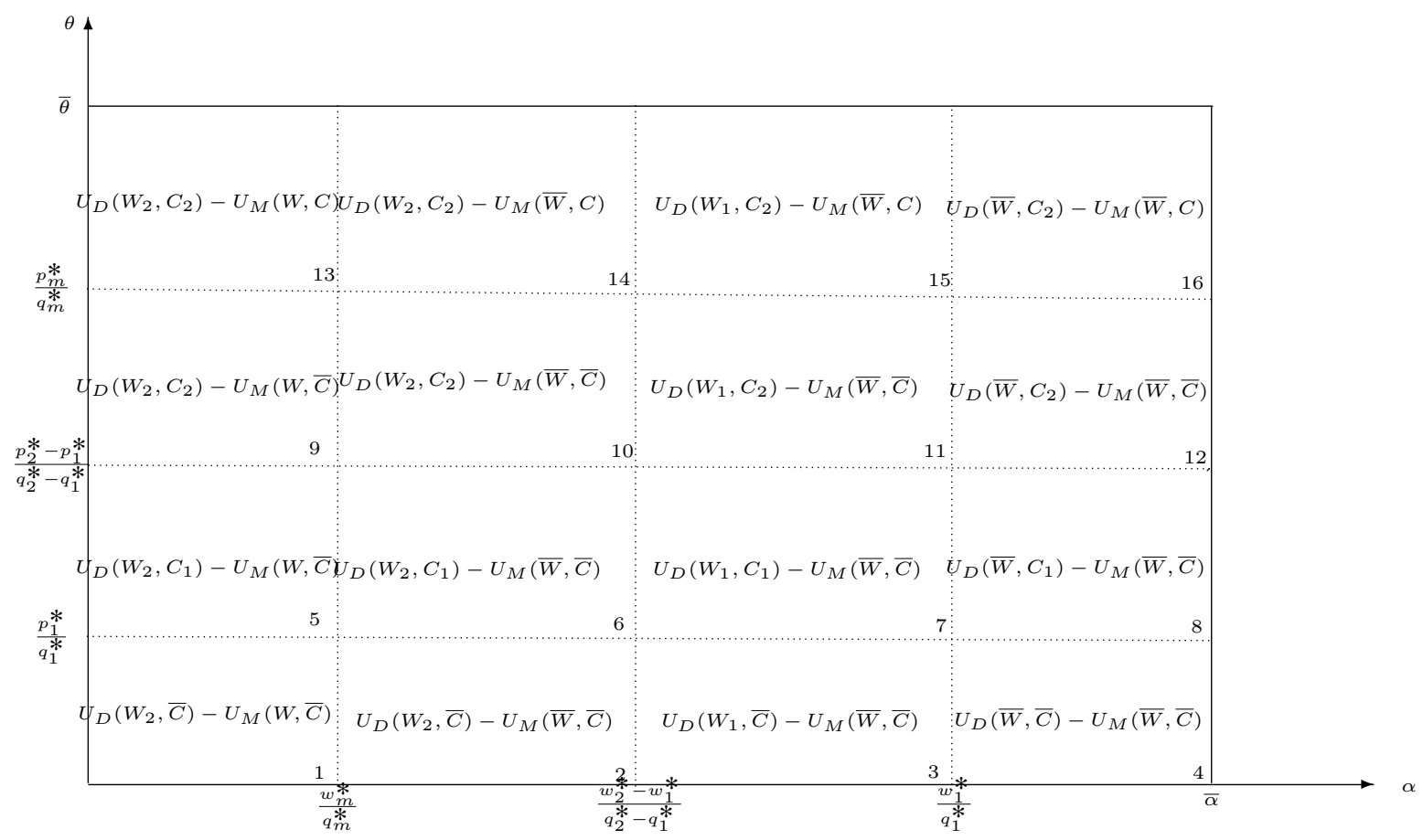

Figure 3: Shareholders' utility difference $U_{D}-U_{M}$.

have that $U_{D}-U_{M}>0$ is equivalent to $\theta>\frac{7}{4} \alpha+\frac{\bar{\theta}}{48(\bar{\theta}+\bar{\alpha})}\left[\left(6+\frac{7}{\mu}\right) \bar{\theta}-15 \bar{\alpha}\right]$.

Denote by $\Delta_{6}$ the straight line defined by the equation $\theta=\frac{7}{4} \alpha+\frac{\bar{\theta}}{48(\bar{\theta}+\bar{\alpha})}\left[\left(6+\frac{7}{\mu}\right) \bar{\theta}-\right.$ $15 \bar{\alpha}]$ in the space $(\alpha, \theta)$. To find the number of consumers who vote either for Duopoly or for Monopoly in Area 6 , we need to study the intersections of $\Delta_{6}$ with the borders of Area 6 . We first calculate the intersections of $\Delta_{6}$ with the vertical borders $\alpha=\frac{w_{m}^{*}}{q_{m}^{*}}$ and $\alpha=\frac{w_{2}^{*}-w_{1}^{*}}{q_{2}^{*}-q_{1}^{*}}$. We second study their positions relatively to $\theta=\frac{p_{1}^{*}}{q_{1}^{*}}$ and $\theta=\frac{p_{2}^{*}-p_{1}^{*}}{q_{2}^{*}-q_{1}^{*}}$. Calculations show three cases depending on $\delta$ and $\mu$, as summarized in Figure 4. 

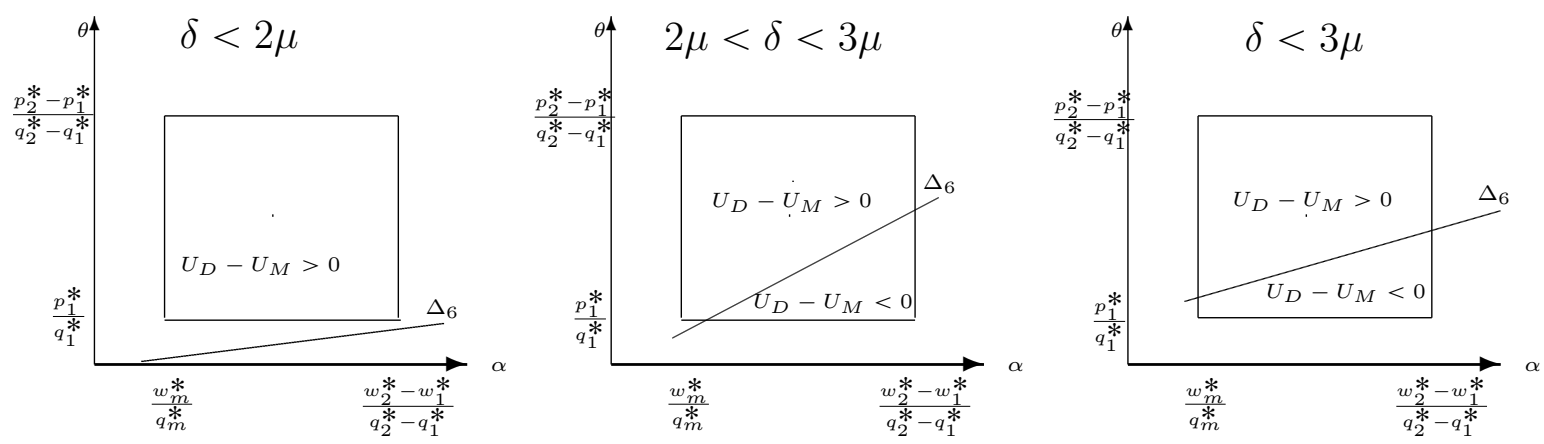

Figure 4: Sign of $U_{D}-U_{M}$ in Area 6 .

\section{Proof of Proposition 1: Step 2}

We compile the discussions from all areas in step 1 and end up with three cases depending on $\mu$ and $\delta$. The difference between the number of people who vote for Monopoly and $\frac{1}{2} \bar{\theta} \bar{\alpha}$ is provided below:

1. If $\delta<2 \mu$ : Results of the majority vote are determined by the sign of $D_{1}(\delta, \mu)=\frac{\bar{\theta} \bar{\alpha}^{3}}{4608 \mu(\bar{\alpha}+\bar{\theta})^{2}}\left[2304 \mu(-1+2 \mu)+96 \mu(-41+12 \mu) \delta+36 \mu(-43+2 \mu) \delta^{2}+7(7+12 \mu) \delta^{3}\right]$ For any $\left.\mu \in] \frac{1}{2}, 1\right]$, there exists a unique $\delta_{\mu} \in[0,2 \mu[$ such that:

- if $\delta<\delta_{\mu}$ then $D_{1}(\delta, \mu)>0$ and the majority vote is for Monopoly.

- if $\delta>\delta_{\mu}$ then $D_{1}(\delta, \mu)<0$ and the majority vote is for Duopoly.

2. If $2 \mu<\delta<3 \mu$ : Results of the majority vote depend on the sign of $D_{2}(\delta, \mu)=\frac{-\bar{\theta} \bar{\alpha}^{3}}{1152 \mu(\bar{\alpha}+\bar{\theta})^{2}}\left[-576 \mu(-1+2 \mu)+3 \mu(328-137 \mu) \delta+2 \mu(301-18 \mu) \delta^{2}+(7+12 \mu) \delta^{3}\right]$ We prove that for any $\left.\mu \in] \frac{1}{2}, 1\right]$ and any $\delta \in[2 \mu, 3 \mu], D_{2}(\delta, \mu)<0$ implying that majority vote is for Duopoly.

3. If $\delta>3 \mu$ : Results of the majority vote depend on the sign of

$$
D_{3}(\delta, \mu)=\frac{-\bar{\theta} \bar{\alpha}^{3}}{48(\bar{\alpha}+\bar{\theta})^{2}}\left[24(-1+2 \mu)+(-41+40 \mu) \delta+(-17+6 \mu) \delta^{2}\right]
$$

We prove that for any $\left.\mu \in] \frac{1}{2}, 1\right]$ and any $\delta>3 \mu, D_{3}(\delta, \mu)<0$ implying that the majority vote is for Duopoly. 